\title{
Turizm Sektörü ve Ekonomik Büyüme: BRICS Ülkeleri ve Türkiye Analizi
}

\author{
Melih Özçalık ${ }^{a, b}$
}

Anahtar Kelimeler

Özet

Turizm sektörü, hizmetler sektörünün en önemli alt kalemlerinden birisidir. Bununla beraber az gelişmiş ve gelişmekte olan ülke ekonomileri için de cari işlemler açıklarını kapatıcı etki yaratan bir sektördür. Turizm sektörü gerek yarattı̆̆ı istihdam gerek ekonomik büyümeyi etkilemesi açısından tüm dünya ekonomileri için vazgeçilmez bir sektör konumundadır. Çalışma, özellikle gelişmekte olan ülke ekonomileri üzerinde durmuştur. Bu ülkeler içerisinde ise BRICS adı verilen ve Brezilya, Rusya Federasyonu, Hindistan, Çin Halk Cumhuriyeti ve Güney Afrika'nın oluşturduğu grup 2000'li yılların ortasından itibaren Dünya ekonomisini etkileyen bir grup haline gelmiştir. Türkiye ekonomisi ise çeşitli makro ekonomik göstergeleri açısından söz konusu ülke grubuyla benzerlik gösterdiği için pek çok bilimsel çalışmada birlikte analiz edilmektedir. Çalışmada 1995-2017 yılları arasında gerçekleşen ve BRICS ülkeleri ile Türkiye'nin dahil olduğu altı ülkenin analiz edildiği bir panel veri çalışması yapılmıştır. GSYİH ile turizm gelirleri arasındaki ilişkinin incelendiği modelde söz konusu değişkenler arasında uzun dönemli bir ilişkinin bulunmadığı, ancak her iki değişken arasında çift yönlü nedensellik bulunduğu sonucuna varılmıştır.

Anahtar Keli
Turizm S
Ekonomik B
Panel Veri
Nedensellik
Makale Hak
Geliş Tarihi: 10.04
Kabul Tarihi: 10.06.
Doi: 10.18026/cbayarsos.717

Abstract

The tourism sector is one of the most important part of the services industry. In addition, this sector has a corrective effect on current account deficits for underdeveloped and developing countries. Tourism sector is an indispensable sector for all countries in terms of employment level and economic growth. The study particularly focused on developing countries. Among these countries, an integration called BRICS, formed by Brazil, Russia, India, China and South Africa, has become effective in world economy since the mid-2000s. Turkey is analyzed together with the BRICS in many scientific studies because of its similar macroeconomic indicators. In this study we established a panel data analysis between 1995-2017 including BRICS and Turkey. We use GDP and tourism receipts in the model. There is no long term relationship in cointegration analysis but there is two sided causality between variables.
Keywords

Tourism Sector

Economic Growth

Panel Data Analysis

Causality Analysis

About Article

Received: 10.04.2020

Accepted: 10.06 .2020

Doi: 10.18026/cbayarsos.717991

\footnotetext{
a İletişim Yazarı: melih.ozcalik@cbu.edu.tr

b Doç. Dr., Manisa Celal Bayar Üniversitesi, İktisadi ve İdari Bilimler Fakültesi, İktisat Bölümü, ORCID: 0000-0002-3559-4975
} 


\section{Giriş}

Turizm sektörü, gerek dış ödemeler bilançosunda yer alan bir kalem olarak gerek gelişmekte olan ve az gelişmiş ülke ekonomilerinin ekonomilerini canlandıran bir hizmetler sektörü unsuru olarak oldukça önemlidir.

Turizm sektörü temel olarak şu alt işletmelerden oluşmaktadır (Arabacı, 2018): Konaklama işletmeleri, yiyecek-içecek işletmeleri, seyahat işletmeleri, rekreasyon işletmeleri.

İkinci Dünya Savaşı'ndan sonra değişen sosyo ekonomik koşullarla turizm sektörü hızla gelişmeye başlamıştır. Günümüzde teknoloji, ulaşım, gelir ve tatillerin artması sonucunda çok hızlı bir şekilde büyüyen turizm sektörü, dünyanın en önemli sektörlerinden birisidir. Bu nedenle, tüm ülkeler vatandaşlarını, turizme üretici veya tüketici olarak katılmaları için teşvik etmektedirler (Kandır vd., 2008).

Ancak bu sektörün yoğun şekilde yükselişe geçmesi 1970'li yıllar sonrasında gerçekleşen küreselleşme olgusu ve bunun beraberinde gelen sermaye hareketleri ve işgücünün hareketliliğinin artışıyladır. İlk başlarda yurtdışında bulunan emek sahiplerinin kendi ülkelerine gelmeleri, daha sonra ise dünya nüfusunda yaşanan gelir artışı, taşımacılık sektörünün yaygınlaşması ve maliyetinin azalışı ile beraber pek çok insanın gerek ülke içinde gerek ülke dışında hareketli hale gelerek turizm sektörünü canlandırmasına yol açmıştır.

Turizmin yaygınlaşması, havacılık sektörü başta olmak üzere taşımacılık sektörünü de oldukça geliştirmiştir. Bu gelişim pek çok istihdamın da gelişmesini beraberinde getirmiştir. Oluşan teknolojik gelişmelerle birlikte taşımacılık maliyetlerinin azalması, özellikle havacılık sektöründe uçak yolcu kapasitelerinin artışı da bu dönemle birlikte gelişmiştir.

Ancak iç ve dış ekonomik, siyasi ve sosyal gelişmeler, özellikle gelişmekte olan ülkelerin turizm sektörünün dalgalı bir seyre sahip olmasına yol açmaktadır. Turizm sektörü, içerisinde yer aldığı hizmetler sektörü ile dış ödemeler bilançosunun önemli bir alt dalını oluşturmaktadır. Özellikle az gelişmiş ve gelişmekte olan ülke ekonomilerinde turizm sektörü, ekonominin sürükleyici sektörüdür. Bu sürükleyicilik, söz konusu ülke ekonomilerinde oldukça fazla görülen cari işlemler açığının da en kısa sürede ancak etkin olmayan kapatma formülü olarak görülmektedir.

Türkiye ekonomisinde turizm sektörünün yükselişe geçmesi ihracata dayalı büyüme modeline geçildiği 24 Ocak 1980 kararlarına kadar uzanır. Bununla birlikte sermayenin serbestleşmesinin önünün açıldığı 1989 yılına kadar bir takım turizm teşvik paketleriyle birlikte turizm sektörünün büyüme üzerindeki etkisi de arttırılmıştır.

Turizm sektörü ile ülkeye giriş yapan sermaye, cari işlemler açığını kapatıcı etki sergilemektedir. Bu durum kriz dönemleri hariç tüm gelişmekte olan ülkeleri ilgilendiren bir durumdur. Cari işlemler bilançosunun açık olmasının sermaye bilançosu ile dengelenme gereksinimi kırılgan yapıya sahip pek çok gelişmekte olan ülkeyi endişelendirmektedir.

Çalışmada ele alınacak olan BRICS ülkeleri beş gelişmekte olan ülkeyi temsil etmektedir. Bunlar: Brezilya, Rusya Federasyonu, Hindistan, Çin Halk Cumhuriyeti ve Güney Afrika'dır. Çalışmanın amacı ise turizm gelirleri ile ekonomik büyüme arasındaki ilişkiye gelişmekte olan ülke gruplarından önemli bir tanesi olan BRICS ve Türkiye açısından bakabilmektir. 


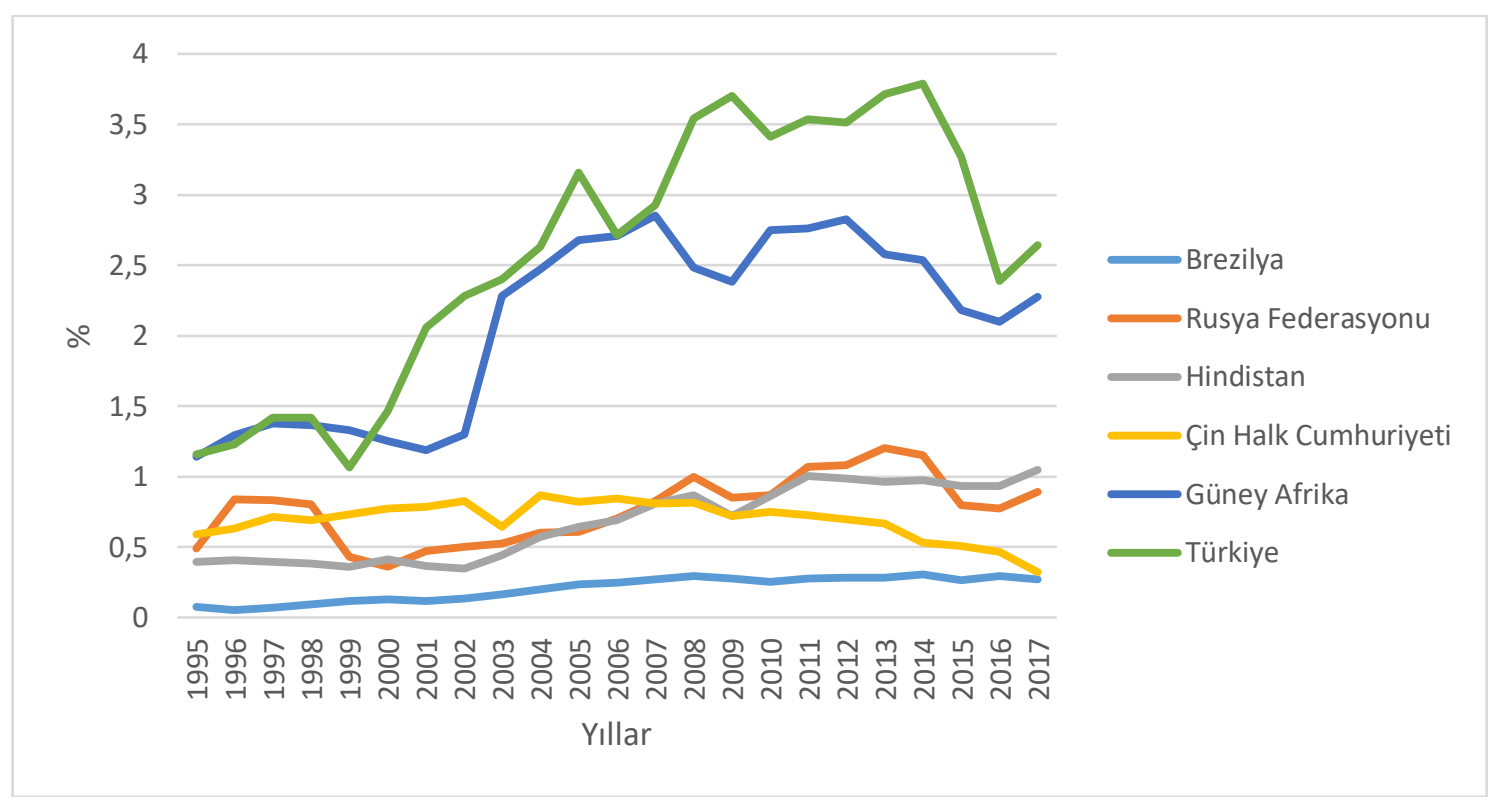

Grafik 1. Turizm Gelirinin GSYİH İçerisindeki Payı

Yukarıdaki tabloda, BRICS ülkeleri ve Türkiye ekonomisinde gerçekleşen turizm gelirlerinin GSYİH içerisindeki oranının yıllar içerisindeki gelişimi yer almaktadır. Buna göre Güney Afrika ve Türkiye'nin turizm gelirlerinin ekonomileri için olan önemi ortaya çıkmaktadır. Bununla beraber, söz konusu dönemde Türkiye ve Güney Afrika'nın turizm gelirlerinin GSYİH'ya oranları diğer ülkelere göre oldukça fazladır. Brezilya'nın ise düşük ama istikrarlı bir yükselişi bulunmaktadır. Bunun yanında, grafikteki dikkat çekici bir nokta, dünya finans tarihinin en kötü krizlerinden birisi olarak nitelendirilebilen 2008 krizi sonrasında grafikteki ülkelerden sadece Türkiye'nin turizm gelirinin milli gelirdeki payını arttırmış olmasıdır. 2014 yılındaki oranda yaşanan yüksek düşüş ise yine Türkiye ekonomisini diğer gelişmekte olan ülkelerden ayrıştıran bir durumdur.

Turizm ile ilgili ekonomik anlamda literatürde yerli ve yabancı çok sayıda bilimsel çalışma bulunmaktadır. Aşağıda bunlardan bazıları incelenecektir.

Dereli ve Akiş (2019) çalışmalarında, 1970-2016 yılları arasında Türkiye'de turizm geliri ve GSYİH artış oranları değişkenlerini ele almıştır ve bu değişkenler arasındaki ilişkiyi eşbütünleşme analizi ile test etmişlerdir. Buna göre her iki değişken arasında uzun dönemli bir ilişki bulunmuştur.

Balıkçığlu ve Oktay (2015), 2003-2014 yıllarını çeyrek dönemler olarak kapsayan çalışmalarında, Türkiye'de turizm geliri ile GSYİH değişkenleri arasındaki ilişkiyi incelemişlerdir. Alınan sonuçlara göre iki değişken arasında uzun dönemli bir ilişki ortaya çıkmıştır. Ayrıca ekonomik büyümeden turizm gelirlerine doğru bir nedensellik ilişkisi de saptanmiştır.

Samırkaş ve Samırkaş (2014) çalışmalarında, 2003-2013 yıllarını çeyrek dönemler olarak incelemişlerdir. Buna göre Türkiye'de reel turizm gelirleri ile reel GSYİH değişkenleri arasında çift yönlü bir nedensellik olduğu sonucuna varılmıştır. 
Bozgeyik ve Yoloğlu (2015), 2002-2014 yıllarını çeyrek dönemler halinde Türkiye'de turizm gelirleri ve GSYİH değişkenlerini incelemişlerdir. Buna göre turizm gelirlerinden ekonomik büyümeye doğru tek yönlü bir nedensellik ilişkisi saptamışlardır.

Bahar (2006), 1963-2004 yılları arasında gerçekleşen dönemde Türkiye'de turizm gelirleri ile ekonomik büyümeyi incelemiştir. Buna göre, iki değişken arasında uzun dönemli ilişki bulunmuştur. Bunun yanında turizm gelirinden ekonomik büyümeye doğru bir nedensellik ilişkisi saptanmıştır.

Kanca (2015) çalışmasında, 1980-2013 yıllarını temel almıştır. Buna göre Türkiye'de ekonomik büyüme değişkeninden turizm gelirlerine doğru nedensellik bulgusuna rastlanmıştır.

Zhang ve Cheng (2019), 2008-2016 yıllarını ele aldıkları çalışmalarında panel veri analizi ile Çin'de yer alan 36 bölgede turizm geliri ile ekonomik büyüme arasında tutarlı bir ilişki bulmuşlardır.

Du vd. (2016), 1995-2011 yılları arasında 109 dünya ülkesini ele aldığ çalışmasında, turizm gelirlerinin büyüme üzerinde anlamlı bir etkisinin olduğunu bulmuşlardır.

Akan vd. (2007), 1985-2007 yılları arasında Türkiye'de gerçekleşen turizm gelirleri ve ekonomik büyüme değişkenlerini ele almıştır. Söz konusu iki değişkenin birbirlerinin nedeni olduğu ve belirtilen dönem boyunca ilişkili oldukları sonucuna varılmıştır.

Işık Maden vd. (2019), 1980-2016 yıllarını ele aldıkları çalışmalarında ARDL modelini kullanarak Türkiye'de turizm geliri ile kişi başına düşen GSYİH ilişkisini ele almışlardır. Model sonucunda kısa ve uzun dönemde söz konusu değişkenler arasındaki ilişki ispatlanmıştır.

Bal vd. (2016), Türkiye'de GSYİH, reel döviz kuru ve turizm gelirlerini ele aldıkları çalışmada dönem olarak 1972-2014 yıllarını seçmişlerdir. Buna göre turizm gelirinde yaşanacak artış milli geliri arttırmaktadır.

Cardenas-Garcia vd. (2015), 1991-2010 yılları arasında 144 ülkeyi incelemiştir. Turizm ve ekonomik büyümeyi ilgilendiren 15 değişken ele alınmıştır. Buna göre, gelişmiş ülke gruplarında turizm gelirleri ekonomik büyümeyi daha fazla arttırmaktadır.

\section{Yöntem ve Bulgular}

Çalışmada 1995-2017 yılları arasında Türkiye ve BRICS ülkeleri olarak belirtilen Brezilya, Rusya Federasyonu, Hindistan, Çin Halk Cumhuriyeti ve Güney Afrika ile gerçekleşen turizm geliri ve ekonomik büyüme arasındaki ilişki incelenmiştir. Tüm veriler Dünya Bankası veri tabanından alınmıştır. Tüm değişkenler logaritmik yapıdadır.

Çalışmada ilk olarak panel veri analizlerinde yatay kesit olarak belirtilen ülke veya ülke gruplarının herhangi birinde yaşanan şokun diğer ülke veya ülke gruplarını etkileyip etkilememesi üzerine kurulan yatay kesit bağımlılığı testi kullanılacaktır. Eğer böyle bir durum söz konusu ise serilerde bulunan birim kökün varlığını birinci nesil panel birim kök testleri ile incelemek daha sonra oluşturulacak denklemlerde hatalı sonuçlar doğuracaktır.

Panel veri setlerinde, yatay kesit bağımlılığını test etmek için kullanılacak başta gelen testler, Pesaran (2004) LMcD testi, Breusch-Pagan (1980) LM testi, ve Pesaran vd. (2008) LMadj. testidir. LM, T>N durumunda yatay kesit bağımlılığı olup olmadığını test eden bir tahmincidir. LMCD testi ise $\mathrm{N}>\mathrm{T}$ durumunda yatay kesit bağımlılığını test eden bir tekniktir (Çınar, 2010: 594). Breusch-Pagan (1980) LM testi, grup ortalaması sıfır fakat bireysel ortalama sıfırdan farklı olduğunda sapmalı olmaktadır. Pesaran vd. (2008), bu sapmayı test 
istatistiğine varyansı ve ortalamayı da ekleyerek düzeltmiştir. Bu nedenle ismi düzeltilmiş LM testi (LMadj.) olarak ifade edilmektedir (Yıldırım vd., 2013). LMadj., gerek ülke sayısının zaman serisinden fazla olması gerek zaman serisinin ülke sayısından büyük olması koşullarında gerçekleştirilebilir.

Tablo 1. Yatay Kesit Bağımlılığı Testi

\begin{tabular}{lcc}
\hline Test & İstatistik & Olasılık \\
\hline LM & 72.18 & 0.0000 \\
LMadj. & 26.65 & 0.0000 \\
LMCD & 5.996 & 0.0000 \\
\hline
\end{tabular}

Tablo 1'e göre seriler arasında yatay kesit bağımlılığı yüzde 1 anlamlılık düzeyinde mevcuttur. Söz konusu yatay kesit bağımlılığı sorununun serilerde bulunması, modelde durağanlığın varlığının sorgulanması için ikinci nesil birim kök testlerini kullanmayı zorunlu kılmaktadır.

Her ülkenin zaman etkilerinden ayrı etkilenmediğini bir bütün panel halinde hareket ettiğini öngören CIPS testi, Pesaran (2007)'nin tablo değerleri ile model sonucunda elde edilen test değerlerinin karşılaştırılması sonucu serilerin birim kök barındırıp barındırmadıklarına karar verir.

Tablo 2. CIPS Durağanlık Testi

\begin{tabular}{lcccc}
\hline Değişkenler (Düzey) & Test & $\mathbf{\% 1}$ & $\mathbf{\% 5}$ & $\mathbf{0 1 0}$ \\
\hline gdp & $-1,056$ & -2.570 & -2.330 & -2.210 \\
tgelir & $-1,915$ & -2.570 & -2.330 & -2.210 \\
\hline Değişkenler (Birinci Fark) & Test & $\mathbf{\% 1}$ & $\mathbf{\% 5}$ & $\mathbf{\% 1 0}$ \\
\hline gdp & $-2,986^{*}$ & -2.570 & -2.330 & -2.210 \\
tgelir & $-4,484^{*}$ & -2.570 & -2.330 & -2.210 \\
\hline
\end{tabular}

Not: Kritik değerler Pesaran (2007) Tablo II(b)'den alınmıştır.

Çalışmada ikinci nesil birim kök testleri arasında paneli bir bütün olarak test eden CIPS testi kullanılmıştır. Buna göre serilerin düzey değerlerinde olmasa da birinci farklarında birim kök barındırmadıkları ve durağan oldukları saptanmıştır. Bu durum gerekli testlerin gerçekleştirilebileceğini göstermektedir.

Swamy S testi, elde edilen modelin homojen bir yapıda olup olmadığına karar veren bir testtir. Elde edilen sonuca göre çeşitli eşbütünleşme ve nedensellik testleri yapılabilmektedir.

Tablo 3. Swamy S Homojenlik Testi

\begin{tabular}{llllllc}
\hline gdp & Katsayılar & Standart Hata & Z Değeri & \multicolumn{1}{c}{$P>|\mathbf{z}|$} & \multicolumn{2}{c}{ \% 95 Güven Aralı̆̆ } \\
\hline tgelir & 0.4986982 & 0.1135756 & 4.39 & 0.000 & 0.276094 & 0.7213023 \\
_cons & 16.21193 & 2.593393 & 6.25 & 0.000 & 11.12898 & 21.29489
\end{tabular}

Ki-Kare (10)= 9271.87

Olasılık $>$ Ki-Kare $=0.0000$ 
Tablo 3'te görülen Swamy S testi sonucuna göre yüzde 1 anlamlllık düzeyinde serilerin heterojen yapıya sahip olduğu alternatif hipotez kabul görmektedir. Buna göre eşbütünleşme testleri ve nedensellik testleri aşağıda yer alanlar gibi seçilmiştir. Bu durumda söz konusu testlerin güvenilirlik düzeyi de artmıştır.

Westerlund eşbütüleşme testi gerek grup olarak gerek bütün paneli dikkate alarak çözümlenebilen bir testtir. Bu test serilerin homojen veya heterojen olma durumlarında da uygulanabilmektedir. Homojenliğe sahip seriler söz konusu olduğunda $\mathrm{Pa}_{a}$ ve $\mathrm{P}_{t}$ değerleri, heterojenlik söz konusu olduğunda ise $G_{a}$ ve $G$ teğerleri dikkate alınmaktadır (Doğanay ve Değer, 2017).

Tablo 4. Westerlund Eş Bütünleşme Testi

\begin{tabular}{llll}
\hline Test & $\mathbf{t}_{\text {test }}$ & $\mathbf{Z}_{\text {test }}$ & Olas1lık \\
\hline $\mathbf{G}_{\mathbf{t}}$ & -1.916 & -0.340 & 0.367 \\
$\mathbf{G}_{\mathbf{a}}$ & -6.898 & 0.137 & 0.554 \\
$\mathbf{P}_{\mathbf{t}}$ & -3.659 & -0.047 & 0.481 \\
$\mathbf{P a}_{\mathbf{a}}$ & -5.687 & -0.710 & 0.239 \\
\hline
\end{tabular}

Tablo 4'te Westerlund eşbütünleşme testi görülmektedir. Olasılık değerleri arasında görülen yüzde 10'dan büyük değerler söz konusu testteki sıfır hipotezin kabul edileceği ve seriler arasında uzun dönemli ilişki olduğunu öngören eşbütünleşme ilişkisinin olmadığına işaret etmektedir. Bu durum homojenlikte ve heterojenlikte söz konusudur.

Dumitrescu-Hurlin panel nedensellik testinin üstün olduğu yanlar; paneli oluşturan ülkeler arasındaki hem yatay kesit bağımlılığını hem de heterojenliği göz önünde bulundurabilmesi, dikey kesit boyutu (T), yatay kesit boyutundan (N) büyük olduğunda da küçük olduğunda da kullanılabilmesi ve dengesiz panel veri setlerinde de etkin sonuçları ortaya çıkarabilmesidir. Bu testin diğer bir özelliği de hem eşbütünleşik ilişkinin varlığında hem de olmadığı durumda analiz yapabilmesidir (Alper ve Oransay, 2015). Çalışmada da eşbütünleşik ilişkinin olmadığ nedensellik testi kullanılmıştır.

Tablo 5. Dumitrescu-Hurlin Nedensellik Testi

\begin{tabular}{lllll}
\hline Nedensellik Yönü & Gecikme & W bar & Z bar & Z bar tilde \\
\hline $\begin{array}{l}\text { tgelir, gdp'nin } \\
\text { nedeni değildir. }\end{array}$ & 5 & 14.6270 & $7.4570(0.0000)$ & $2.3113(0.0208)$ \\
$\begin{array}{l}\text { gdp, tgelir'in } \\
\text { nedeni değildir. }\end{array}$ & 2 & 7.1831 & $6.3480(0.0000)$ & $4.5452(0.0000)$ \\
\hline
\end{tabular}

Tablo 5'te Dumitrescu-Hurlin panel nedensellik testi yer almaktadır. Buna göre olasılık değerlerinin en az yüzde 2 anlamlılık düzeyinde bulunması, değişkenler arasında iki yönlü bir nedensellik ilişkisinin varlığına işaret etmektedir. 


\section{Sonuç}

Turizm sektörünün önemi, insanoğlunun toplumsal yaşama geçmesi, iş hayatının yoğunlaşması ve tatil kavramının öneminin artmaya başlaması ile birlikte artmıştır. Bunun yanı sıra 1970'li yıllardan itibaren küreselleşme olgusunun tüm dünyayı gerek sermaye gerek sosyal olarak bir araya getirmesiyle yabancı kültürlere doğan ilgi de turizm sektörünün önünü açan önemli bir gelişmedir.

Turizm sektörü, daha çok içinde barındırdığı tur, gezi, kültür ve coğrafya kelimeleri ile birlikte anılmasının yanı sıra ekonomik anlamda da oldukça önemli bir sektördür. Dış ödemeler bilançosunda yer alan hizmetler hesabında bulunan bir kalem olan turizm sektörü, özellikle cari işlemler hesabının dış ticaret alt kaleminde açık problemi çeken gelişmekte olan ve az gelişmiş ülke ekonomilerinin sermaye hesabının yükünü hafifleten bir sektördür. $\mathrm{Bu}$ sektör, az gelişmiş ve gelişmekte olan ülkelerde daha çok coğrafi yapı ile kültür ile ilgili konularda yoğunlaşırken, gelişmiş ülkelerde özellikle önemli şehirlere düzenlenen turlar üzerinde yoğunlaşmaktadır.

Turizm sektörünün gelişmesi ile birlikte özellikle sermaye sıkıntısı çeken ve yatırımlarını arttıramayan gelişmekte olan ülke ekonomileri, turizm sektöründen elde ettikleri sermaye ile birlikte yatırımlarını geliştirerek milli gelirlerini arttırma yoluna gitmişlerdir. Bununla birlikte iç ve dış siyasi, stratejik ve hatta olumsuz ekonomik gelişmeler, turizm sektörünün zaman zaman önünü kesen gelişmeler olabilmektedir. Bu durum özellikle kırılgan yapıya sahip gelişmekte olan ülke gruplarının önündeki önemli bir engeldir.

Çalışmada 1995-2017 yılları ele alınarak dünyada önemli gelişmekte olan ülkelerden oluşan bütünleşmelerden birisi olan BRICS ve Türkiye ekonomisi incelenmiştir. Bu incelemede yıllık GSYİH verileri ve turizm gelirleri ele alınmıştır. Yıllık verilerle incelenen çalışmada her iki değişkenin de doğal logaritması alınmıştır. Yatay kesit bağımlılı̆̆ının bulunduğu serilere ikinci nesil panel birim kök testi uygulanmıştır. Her iki serinin uzun dönemli ilişkisinin incelendiği Westerlund eşbütünleşme testinde uzun dönemli bir ilişkinin bulunmadığ1 saptanmış ve literatürdeki birçok çalışmadan bu sebeple ayrılmıştır. Bunun yanında, her iki değişkenin de karşılıklı olarak birbirinin nedeni olduğu Dumitrescu-Hurlin panel nedensellik testi ile saptanmıştır.

Buna göre ele alınan altı gelişmekte olan ülke ekonomisinde turizm gelirleri ile ekonomik büyüme arasında birbirlerini ilgilendiren bir nedensellik olmasına karşın uzun dönemli bir ilişkiye sahip olmamaları, söz konusu ülke ekonomilerinin iç ve dış pek çok konjonktürel gelişmenin bu ilişkiyi zaman zaman kesintiye uğratması olarak görülebilir. Bu durum daha önce de sözü edilen kırılgan yapıya sahip gelişmekte olan ülke ekonomilerinin yalnızca turizm sektörüne bağlı kalarak ekonomik büyümelerini veya açık olan cari işlemler hesaplarını düzenleyemeyeceklerini de kanıtlar niteliktedir.

Bu sonuçlar ışığında, gelişmekte olan ülke ekonomilerinin yaşayabilecekleri dış ödemeler bilançosu dengesizliklerini daha çok uzun vadeli sermayeyi ekonomilerine çekmeleri gösterilebilir. Ülke ekonomisine katılacak olan uzun vadeli sermaye, gerek yaratacağ istihdam gerek ekonomiye sağlayacağı vergi gelirleri ile birlikte uzun vadeli bir gelişmenin kapısını aralayacağı söylenebilir. Ancak, söz konusu sermayenin bu ülke gruplarına gelmesinin önünde bazı engeller bulunabilmektedir. Uzun vadeli sermayenin ekonomiye dahil olması, sadece ülke içinde belirlenebilecek faiz oranları ile değil uluslararası olarak 
belirlenen döviz kuru, ülkede uygulanan döviz kuru sistemi ve kredi temerrüt takası gibi pek çok ekonomik ve finansal değişkene göre belirlendiğini de açıktır.

\section{Kaynakça}

Akan, Y., Arslan, İ. \& Işık, C. (2007). The Impact of Tourism on Economic Growth: The Case of Turkey. Journal of Tourism, 9, 1-24.

Alper, A.E. \& Oransay, G. (2015), Cari Açık ve Finansal Gelişmişlik İlişkisinin Panel Nedensellik Analizi Ekseninde Değerlendirilmesi. Uluslararası Ekonomi ve Yenilik Dergisi, $1(2), 73-85$.

Arabacı, H. (2018). Turizm Sektörünün Ekonomik Büyümeye Etkisi Üzerine Teorik Bir İnceleme. Balkan ve Yakın Doğu Sosyal Bilimler Dergisi, 4(3), 104-109.

Bahar, O. (2006). Turizm Sektörünün Türkiye'nin Ekonomik Büyümesi Üzerindeki Etkisi: VAR Analizi Yaklaşımı. Yönetim ve Ekonomi Dergisi, 13(2), 137-150.

Bal, H., Akça, E.E. \& Bayraktar, M. (2016). The Contribution of Tourism to Economic Growth: A Research on the Turkey. Akademik Yaklaşımlar Dergisi, 7(1), 1-20.

Balıkçığlu, E. \& Oktay, K. (2015). Türkiye'de Turizm Gelirleri ve Ekonomik Büyüme İlişkisinin Kamu Politikaları Doğrultusunda Değerlendirilmesi. Sosyoekonomi, 23(25), 113125.

Bozgeyik, Y. \& Yoloğlu, Y. (2015). Türkiye'de Turizm Gelirleri İle GSYH Arasındaki İlişki: 2002-2014 Dönemi. Uluslararası Sosyal Araştırmalar Dergisi, 8(40), 627-640.

Breusch, T.S. \& Pagan, A.R. (1980). The Lagrange Multiplier Test and Its Applications to Model Specification in Econometrics. Review of Econometric Studies, 47(1), 239-253.

Cardenas-Garcia, P.J. Sanchez-Rivero, M. \& Pulido-Fernandez, J.I. (2015). Does Tourism Growth Influence Economic Development? Journal of Travel Research, 54(2) 206-221.

Çınar, S. (2010). OECD Ülkelerinde Kişi Başına GSYİH Durağan Mı? Panel Veri Analizi. Marmara Üniversitesi İİBF Dergisi, 24(2), 591-601.

Dereli, D.D. \& Akiş, E. (2019). Türkiye'de Turizm Gelirleri ile İktisadi Büyüme Arasındaki İlişkinin Analizi (1970-2016). Atatürk Üniversitesi İktisadi ve İdari Bilimler Fakültesi Dergisi, 33(2), 467-477.

Doğanay, M.A. \& Değer, M.K. (2017). Yükselen Piyasa Ekonomilerinde Doğrudan Yabancı Yatırımlar ve İhracat İlişkisi: Panel Veri Eşbütünleşme Analizleri (1996-2014). Çankırı Karatekin Üniversitesi İktisadi ve İdari Bilimler Fakültesi Dergisi, 7(2), 127-145.

Du, D., Ng, P. \& Lew, A.A. (2016). Tourism and Economic Growth. Journal of Travel Research, 55(4), 454-464.

Kanca, O.C. (2015). Turizm Gelirleri ve Ekonomik Büyüme: Türkiye Örneği (1980-2013). Marmara Sosyal Araştırmalar Dergisi, Aralık, 1-14.

Kandır, S.Y., Karadeniz, E., Özmen, M. \& Önal, Y.B. (2008). Türk Turizm Sektöründe Büyüme Göstergelerinin Turizm İşletmelerinin Finansal Performansına Etkisinin İncelenmesi. Dokuz Eylül Üniversitesi Sosyal Bilimler Enstitüsü Dergisi, 10(1), 211-237. 
Maden, S.I., Bulgan, G. \& Yıldirım, S. (2019). The Effect of Tourism Sector on Economic Growth: An Empirical Study on Turkey. Journal of Yaşar University, 14(55), 215-225.

Pesaran, M.H. (2004). General Diagnostic Tests for Cross Section Dependence in Panels; CESifo Working Paper, No. 1229; Center for Economic Studies and Ifo Institute (CESifo): Munich, Germany.

Pesaran, M.H. (2007). A Simple Panel Unit Root Test in The Presence Of Cross-Section Dependence. Journal of Applied Econometrics, 22(2), 265-312.

Pesaran, M.H., Ullah, A. \& Yamagata, T.A. (2008). Bias-Adjusted LM Test of Error Cross Section Independence. The Econometrics Journal, 11(1), 105-127.

Samırkaş, M. \& Samırkaş, M.C. (2014). Turizm Sektörünün Ekonomik Büyümeye Etkisi: Türkiye Örneği. Dokuz Eylül Üniversitesi İşletme Fakültesi Dergisi, 15(1), 63-76.

Yıldırım, K., Mercan, M. \& Kostakoğlu, S.F. (2013). Satın Alma Gücü Paritesinin Geçerliliğinin Test Edilmesi: Zaman Serisi ve Panel Veri Analizi. Eskişehir Osmangazi Üniversitesi İ̈BF Dergisi, 8(3), 75-95.

Zhang, J. \& Cheng, L. (2019). Threshold Effect of Tourism Development on Economic Growth Following a Disaster Shock: Evidence from the Wenchuan Earthquake, P.R. China. Sustainability, 11(2), 371-393. 